\title{
Metabolites Produced by a New Lactiplantibacillus plantarum Strain BF1-13 Isolated from Deep Seawater of Izu-Akazawa Protect the Intestinal Epithelial Barrier from the Dysfunction Induced by Hydrogen Peroxide
}

\author{
Xiaozhen Diao ${ }^{1, *}$, Katsuhisa Yamada ${ }^{1,2}$, Yuji Shibata ${ }^{2}$ and Chiaki Imada ${ }^{1}$ \\ 1 Applied Microbiology Lab, Course of Applied Marine Biosciences, Graduate School of Marine Science and \\ Technology, Tokyo University of Marine Science and Technology, Tokyo 108-8477, Japan; \\ k-yamada@dhc.co.jp (K.Y.); imada@kaiyodai.ac.jp (C.I.) \\ 2 DSW Laboratory of DHC Co., Ltd., Tokyo 106-0047, Japan; yshibata@dhc.co.jp \\ * Correspondence: littletruth119@gmail.com
}

Citation: Diao, X.; Yamada, K.; Shibata, Y.; Imada, C. Metabolites Produced by a New Lactiplantibacillus plantarum Strain BF1-13 Isolated from Deep Seawater of Izu-Akazawa Protect the Intestinal Epithelial Barrier from the Dysfunction

Induced by Hydrogen Peroxide. Mar. Drugs 2022, 20, 87. https://doi.org/ $10.3390 / \mathrm{md} 20020087$

Academic Editors: Elena Talero and Javier Ávila-Román

Received: 2 December 2021 Accepted: 18 January 2022

Published: 20 January 2022

Publisher's Note: MDPI stays neutral with regard to jurisdictional claims in published maps and institutional affiliations.

Copyright: (c) 2022 by the authors. Licensee MDPI, Basel, Switzerland. This article is an open access article distributed under the terms and conditions of the Creative Commons Attribution (CC BY) license (https:/ / creativecommons.org/licenses/by/ $4.0 /)$.

\begin{abstract}
This study aimed to investigate the protective effect of the metabolites produced by a new Lactiplantibacillus plantarum strain BF1-13, isolated from deep seawater (DSW), on the intestinal epithelial barrier against the dysfunction induced by hydrogen peroxide $\left(\mathrm{H}_{2} \mathrm{O}_{2}\right)$ and to elucidate the mechanism underlying the effect. Protective effect of the metabolites by strain BF1-13 on the barrier function of the intestinal epithelial model treated with $\mathrm{H}_{2} \mathrm{O}_{2}$ was investigated by the transepithelial electrical resistance (TEER). The metabolites enhanced the Claudin-4 (CLDN-4) expression, including at the transcription level, indicated by immunofluorescence staining and quantitative RT-PCR. The metabolites also showed a suppression of aquaporin3 (AQP3) expression. Lactic acid (LA) produced by this strain of homofermentative lactic acid bacteria (LAB) had a similar enhancement on CLDN-4 expression. The metabolites of L. plantarum strain BF1-13 alleviated the dysfunction of intestinal epithelial barrier owing to its enhancement on the tight junctions (TJs) by LA, along with its suppression on AQP3-facilitating $\mathrm{H}_{2} \mathrm{O}_{2}$ intracellular invasion into Caco-2 cells. This is the first report on the enhancement of TJs by LA produced by LAB.
\end{abstract}

Keywords: Lactiplantibacillus plantarum; deep seawater; tight junctions; aquaporin3; hydrogen peroxide; lactic acid

\section{Introduction}

It is known that the intestinal epithelium basically functions for the maintenance of the internal environment [1]. It absorbs nutrients and defends the exogenous pathogens and their secretion of toxins to protect the human body from diseases, including inflammatory bowel disease (IBD), celiac diseases, and diarrhea [2]. Between the intestinal epithelial cells, there exist TJs mediating the paracellular permeability to achieve the barrier function.

TJs are complex, contiguous, relatively, and dynamically impermeable junctional devices that take up the most apical surface of the intercellular space of intestinal epithelium [3]. TJs consist of several functional proteins including claudins, occludin (OCLN), tricellulin, and junctional adhesion molecules. The barrier function of the intestinal epithelium is closely related to these functional proteins' expression [4]. TEER assay with the intestinal epithelial model constructed by Caco-2 cells has been widely used to investigate the integrity of the intestinal epithelial barrier [5].

However, the function of TJs can be degraded by some reactive oxygen species, such as $\mathrm{H}_{2} \mathrm{O}_{2}$ [6]. $\mathrm{H}_{2} \mathrm{O}_{2}$ can be generated from the endogenous, such as the antibacterial defense by immune response or from the exogenous, such as unhealthy lifestyle, environmental pollution, and aging. Although the $\mathrm{H}_{2} \mathrm{O}_{2}$ at a low level can participate in cell signaling and cell proliferation and can eliminate invading pathogens, the high concentration may 
induce oxidative stress-related diseases, such as diabetes and inflammatory bowel disease in the case of the gastrointestinal tract $[7,8]$. Oxidative stress induced by different kinds of reactive oxygen species has been proven to cause the disruption of intestinal epithelial TJs [9]. It has been recently reported that the transportation of endogenous $\mathrm{H}_{2} \mathrm{O}_{2}$ facilitated by peroxiporins such as AQP3 (transcellular invasion) occurs prior to simple diffusion (paracellular invasion) [10].

The gut microbiota maintains the integrity and function of the gastrointestinal tract, where there are colonies of the huge community of LA-producing bacteria such as LABs [11]. LA was found as an impure component from sour milk in 1780, which was proven to be an isolated metabolite of microorganisms by Pasteur in 1857. In 1881, a French scientist successfully produced it by microbial fermentation, which leads to the first boom of LA industrial production. Since then, LA has been continuously among the hot spots in many industries, such as the food, probiotics, medical, cosmetic, and pharmaceutical industry. From the 2000s, its biotechnological application to form polylactic acid (PLA) has been of increasing interest [12]. Due to its advantage with lower cost, less limitation on production, high efficiency, and being eco-friendly, bacterial fermentation takes up about $90 \%$ of the industry market of LA production [13]. So far, there is no report on the effect of LA on the intestinal epithelial barrier function, although there are many about the LAB themselves.

Grishina et al. [14] proved that kefir and ayran supernatants, which contain large amounts of LA, decreased DNA damage in colon cells caused by fecal water in vitro. However, according to them, no effect on intestinal TJs was observed. Kefir \& ayran (fermented milk) fermented by complicated bacterial species produce various components in the culture supernatants, including not only lactic acid but also other organic substances, such as ethanol [15]. Due to all these reasons, their results cannot be convincing evidence for the effect of LA on TJs. In contrast, Forsyth G. W. et al. [16] reported that L-LA reduced the net fluid secretion in ligated jejunal loops in vitro caused by cholera toxin, which indicated the potential effect of LA on intestinal epithelial permeability regulated by TJs.

It has been proven that the intestinal oxidative damage induced by $\mathrm{H}_{2} \mathrm{O}_{2}$ can be inhibited or released by some species of Lactobacillus, mostly isolated from the probiotics, $[17,18]$ or by the fermentative products of them [19]. Although homofermentative LAB mainly refers to both L. plantarum and Lactobacillus delbrueckii, unlike the former, L. delbrueckii, which can convert $95 \%$ of glucose into LA, only produces D-LA [16], which was reported to be harmful by inducing acidosis and de-calcification [20]. The L. plantarum strain JCM11125 (also as L. arizonensis strain; 1474 bp; ENA accession number AJ965482) isolated from jojoba meal fermentation is a homofermentative strain with no catalase production and had a wide range of growth temperatures [21], which was used as the standard strain in this study.

This study aims to investigate the protective effect of the metabolites produced by DSW-derived L. plantarum strain BF1-13 on the intestinal epithelial barrier against the $\mathrm{H}_{2} \mathrm{O}_{2}$-induced dysfunction and its underlying mechanism related to the AQP-facilitating $\mathrm{H}_{2} \mathrm{O}_{2}$ intracellular invasion. Furthermore, it provides the potential application of the strain BF1-13 fermented food and its metabolites as supplements for IBD patients.

\section{Results}

\subsection{Characteristics of Three Lactiplantibacillus Strains}

The two isolated L. plantarum strains were confirmed by $16 \mathrm{~S}$ rRNA gene sequencing and named as BF1-13 (1492 bp; DDBJ accession number LC666821) and H-6 (1492 bp; DDBJ accession number LC666820), respectively.

These three strains showed nearly the same characteristics. There is no difference in salt tolerance among the strains, whose maximum tolerances were $5 \% \mathrm{NaCl}$. Similar to the standard strain JCM11125, both of the two isolated strains were able to ferment all kinds of substrates and survived in the nutrients-limited medium only supplemented with specific carbohydrates All strains grew at a $\mathrm{pH}$ range of 2-9. However, strain BF1-13 failed to grow at $20^{\circ} \mathrm{C}$ and showed a preference for a higher temperature $\left(27-40^{\circ} \mathrm{C}\right)$. (Table 1$)$ 
Table 1. Comparison of growth characteristics of the three strains.

\begin{tabular}{|c|c|c|c|c|}
\hline & & Strain BF1-13 & Strain JCM11125 & Strain H-6 \\
\hline \multirow{7}{*}{ Temperature $\left({ }^{\circ} \mathrm{C}\right)$} & 5 & - & - & - \\
\hline & 10 & - & - & - \\
\hline & 20 & - & + & + \\
\hline & 27 & + & + & + \\
\hline & 37 & + & + & + \\
\hline & 40 & + & + & + \\
\hline & 45 & - & - & - \\
\hline \multirow{7}{*}{$\mathrm{pH}$} & 2 & + & + & - \\
\hline & 3 & + & + & + \\
\hline & 4 & + & + & + \\
\hline & 6.5 & + & + & + \\
\hline & 9 & + & + & + \\
\hline & 10 & - & - & - \\
\hline & 11 & - & - & - \\
\hline \multirow{6}{*}{$\mathrm{NaCl}(\%, m / v)$} & 0 & + & + & + \\
\hline & 1 & + & + & + \\
\hline & 2 & + & + & + \\
\hline & 3 & + & + & + \\
\hline & 5 & + & + & + \\
\hline & 10 & - & - & - \\
\hline \multirow{7}{*}{ Fermentation substrate } & Glucose & + & + & + \\
\hline & Sorbitol & + & + & + \\
\hline & Trehalose & + & + & + \\
\hline & Xylose & + & + & + \\
\hline & Arabinose & + & + & + \\
\hline & Mannitol & + & + & + \\
\hline & Lactose & + & + & + \\
\hline
\end{tabular}

+, growth; -, no growth $(n=3)$.

During the $12 \mathrm{~h}$ incubation ( $\mathrm{pH}$ 6.5) at $37^{\circ} \mathrm{C}$, strain BF1-13 showed superiority in cell growth with the other two strains. Among the three strains, strain BF1-13 showed the fastest growth $\left(1.67 \times 10^{9} \mathrm{CFU} / \mathrm{mL}\right.$, Figure 1a), and the most remarkable decreasing $\mathrm{pH}$ value ( $\mathrm{pH} 4.599)$ (Figure 1b). From the measurement of the concentration of LA contained in each culture supernatant (CS), it was suggested that there was a little difference in the LA production during $12 \mathrm{~h}$ incubation in the following groups: strain BF1-13 $(26.3 \mathrm{mM})$, strain H-6 (20.0 mM), the standard strain JCM11125 (19.8 mM) (Table 2). As mentioned above, strain BF1-13 was selected as the research target because it showed superiority in growth and LA accumulation. Strain JCM 1112 was prepared as the standard strain in this study.

Table 2. Characteristics of each strain after $12 \mathrm{~h}$ incubation.

\begin{tabular}{cccc}
\hline Strain & BF1-13 & JCM11125 & H-6 \\
\hline $\mathrm{CFU} / \mathrm{mL}$ & $1.67 \times 10^{9}$ & $7.44 \times 10^{8}$ & $8.71 \times 10^{8}$ \\
\hline $\mathrm{pH}$ & 4.6 & 4.9 & 4.9 \\
\hline Latic acid $(\mathrm{mM})$ & 26.3 & 19.8 & 20.0 \\
\hline
\end{tabular}

The number of bacterial cells indicates as $\mathrm{CFU} / \mathrm{mL}(n=9$, mean \pm SD). 


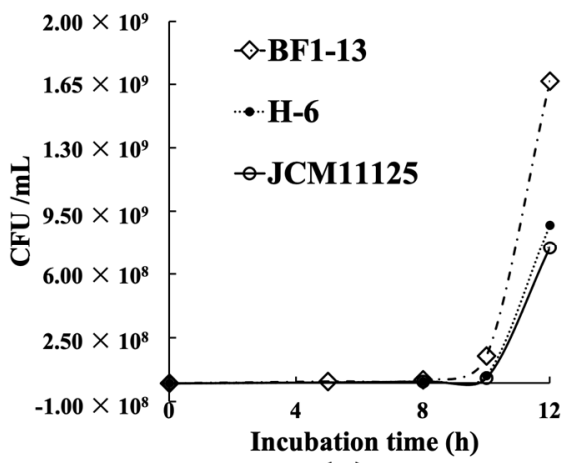

(a)

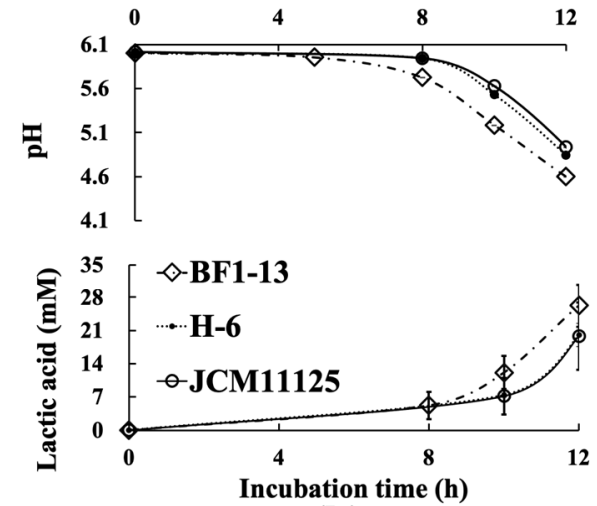

(b)

Figure 1. Comparison of each strain (BF1-13 $\downarrow, \mathrm{H}-6 \lambda$, JCM11125 $\gamma$ ) on various characteristics. (a) The growth curve of the three strains. (b) The amounts of LA and $\mathrm{pH}$ changing of each strain during $12 \mathrm{~h}$ incubation. Data are shown as means $\pm \mathrm{SD}, n=9$.

2.2. Protection on the Intestinal Epithelial Barrier by the Metabolites Produced by Strain BF1-13 against the Dysfunction Caused by $\mathrm{H}_{2} \mathrm{O}_{2}$ Treatment in Caco-2 Cells

TCTEER values decreased to $45.1 \%$ of the initial values after $6 \mathrm{~h} \mathrm{H}_{2} \mathrm{O}_{2}$ treatment on the intestinal epithelial model using Caco- 2 cells. The decreasing tcTEER value by $\mathrm{H}_{2} \mathrm{O}_{2}$ treatment was suppressed by the supplementation of $5 \%(v / v)$ CS of strain BF1-13. At the same supplemented concentration of $5 \%(v / v)$ of the CSs, strain BF1-13 $(62.2 \%)$ showed slightly higher TEER values than standard strain (59.9\%) (Figure 2b). However, this effect of the CS of strain BF1-13 disappeared by the $10 \%(v / v)$ supplementation (28.3\%). (Figure 2a).

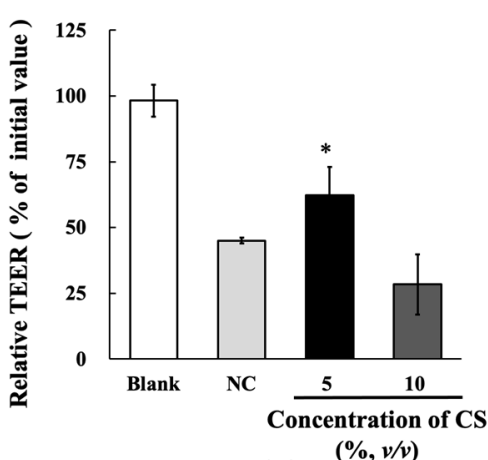

(a)

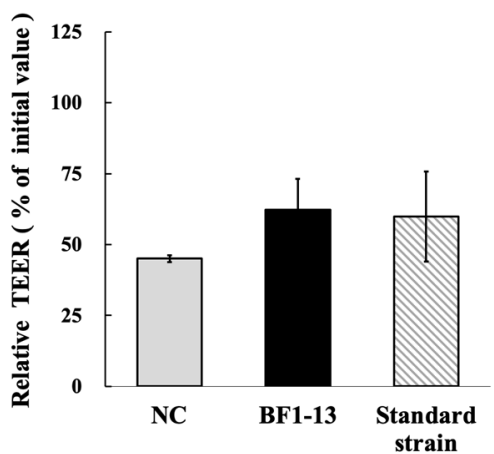

(b)

Figure 2. Effects of the metabolites of strain BF1-13 (black) and standard strain (slashes) on TJs barrier function in human Caco-2 cells. (a) The relationship between relative TEER value and CS supplemented concentration with $1 \mathrm{mM} \mathrm{H}_{2} \mathrm{O}_{2}$ (NC) or without (blank). (b) The comparison of the protective effect between the metabolites of the two strains on TJs barrier function. Monolayers were preincubated with $5 \%(v / v)$ CS of the two strains separately or without (NC) for $2 \mathrm{~h}$, followed by $1 \mathrm{mM} \mathrm{H}_{2} \mathrm{O}_{2}$ treatment for $6 \mathrm{~h}$ or not (blank). Relative TEER values are means $\pm \mathrm{SD}, n=3$. Asterisks indicate a significant difference with NC $\left({ }^{*} p<0.05\right)$ determined by the Mann-Whitney U test.

2.3. Enhancement on the TJs-Related Proteins by the Metabolites Produced by Strain BF1-13 from the Suppression Induced by $\mathrm{H}_{2} \mathrm{O}_{2}$

2.3.1. Enhancement on CLDN-4 by the Metabolites Produced by Strain BF1-13 through Immunofluorescent Microscopy

Decreasing expression of CLDN-4 by $\mathrm{H}_{2} \mathrm{O}_{2}$ treatment was inhibited by the supplementation of the CS of the strain BF1-13. This effect was also shown on the standard strain (Figure 3). However, the expression of OCLN was different from that of CLDN-4. There was a little difference between the metabolites of the two strains. In the case of strain 
BF1-13, the difference of the effects between supplemented concentration $5 \%$ and $10 \%$ was barely seen with the immunofluorescent staining microscopy (Data not shown.)

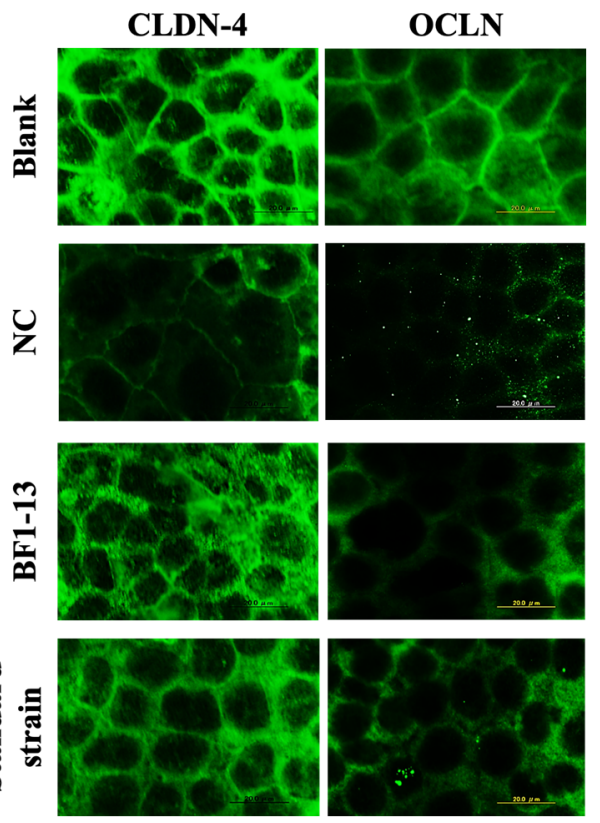

Figure 3. The comparison of the enhancements between the metabolites of the two strains on the expression of CLDN-4 and OCLN. Monolayers were preincubated with 5\% $(v / v)$ CS of the two strains separately or without (NC) for $2 \mathrm{~h}$, followed by $1 \mathrm{mM} \mathrm{H}_{2} \mathrm{O}_{2}$ treatment for $2 \mathrm{~h}$ or not (blank). Images were observed by fluorescence microscopy. Each image is representative of 3 similar experiments. The scale bar is $20 \mu \mathrm{m}$.

\subsubsection{Inducement on CLDN-4 mRNA by the Metabolites Produced by Strain BF1-13} through Quantitative RT-PCR

The mRNA expression of CLDN-4 was only induced by the supplementation with the CS of the strain BF1-13 in Caco-2 cells (Figure 4a). The mRNA expression of CLDN-4 with the supplementation with the CS of strain BF1-13 (fold-change of $1.75 \& 1.53$ ) was higher than that with the $\mathrm{NC}$ (fold-change of $1.20 \& 1.15$ ) during the $2 \mathrm{~h} \mathrm{H}_{2} \mathrm{O}_{2}$ treatment. However, enhancement of CLDN-4 expression was not shown on that treatment with the CS of the standard strain (fold-change of $0.85 \& 0.91$ ). In the case of OCLN, the mRNA expression was not maintained by the supplementations with the CSs of both two strains (Figure 4b).

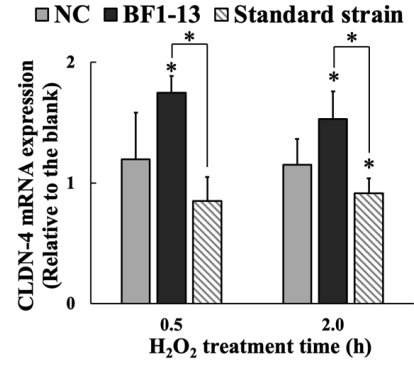

(a)

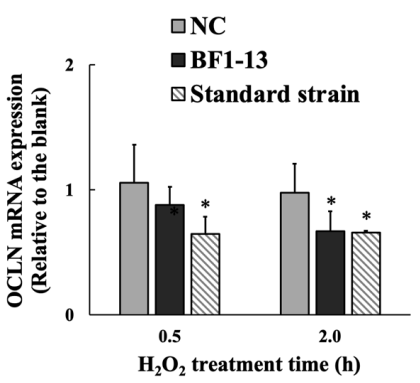

(b)

Figure 4. The inducement of the metabolites of the strain BF1-13 (black) on the expression of CLDN-4 (a) at the transcription level compared with the standard strain (slashes), which was compared with the expression of OCLN (b). Monolayers were preincubated with 5\% (v/v) CS of the two strains separately or without (NC) for $2 \mathrm{~h}$, followed by $1 \mathrm{mM} \mathrm{H}_{2} \mathrm{O}_{2}$ treatment for 0.5 and $2 \mathrm{~h}$ separately or not (blank). The mRNA expressions relative to the blank are shown as means $\pm \mathrm{SD}, n=3$. Asterisks indicate a significant difference with the blank, or between BF1-13 and the standard strain $\left({ }^{*} p<0.05\right)$ determined by the Mann-Whitney U test. 


\subsection{Suppression on AQP3 by the Metabolites Produced by Strain BF1-13}

2.4.1. Suppression on AQP3 by the Metabolites Produced by Strain BF1-13 through Immunofluorescent Microscopy

The expression of AQP3 was enhanced by $1 \mathrm{mM} \mathrm{H}_{2} \mathrm{O}_{2}$ treatment compared to the blank, which was also supported by the previous report [10]. The AQP3 expression was suppressed by the supplementation with the CS of strain BF1-13. Then, the same effect was shown in the CS of the standard strain (Figure 5).

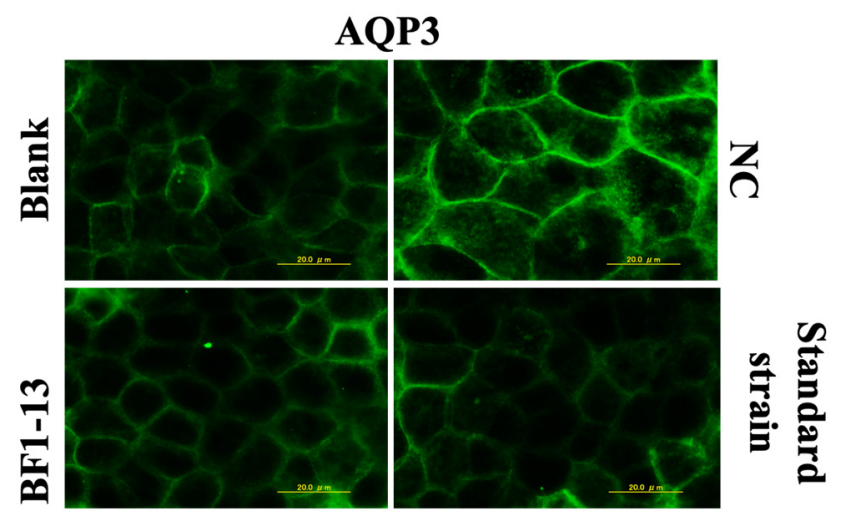

Figure 5. The suppressions of the AQP3 expression in human Caco-2 cells induced by the supplementation of the CSs. Monolayers were preincubated with 5\% $(v / v)$ CS of the two strains separately or without (NC) for $2 \mathrm{~h}$, followed by $1 \mathrm{mM} \mathrm{H}_{2} \mathrm{O}_{2}$ treatment for $2 \mathrm{~h}$ or not (blank). Images were observed by fluorescence microscopy. Each image is representative of 3 similar experiments. The scale bar is $20 \mu \mathrm{m}$.

2.4.2. Suppression on AQP3 mRNA by the Metabolites Produced by Strain BF1-13 through Quantitative RT-PCR

The mRNA expression of AQP3 was significantly suppressed by the metabolites by strain BF1-13. This suppression was also shown on the metabolites by the standard strain (Figure 6). The mRNA expression of AQP3 with the supplementation with the CS of strain BF1-13 (fold-change of $0.57 \& 0.52$ ) was strongly suppressed during the $2 \mathrm{~h} \mathrm{H}_{2} \mathrm{O}_{2}$ treatment, as well as that of the standard strain (fold-change of $0.45 \& 0.45$ ).

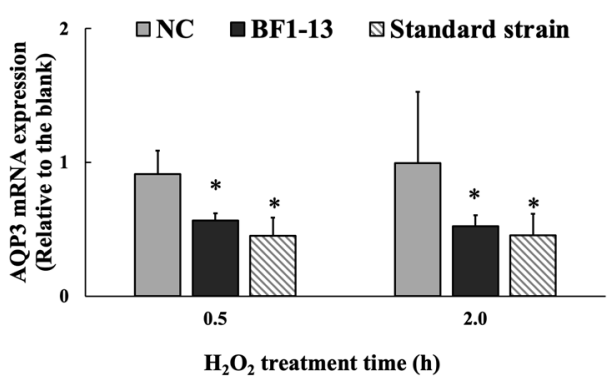

Figure 6. The suppressions of the metabolites of strain BF1-3 (black) and standard strain (slashes) on the expression of AQP3 at the transcription level. Monolayers were preincubated with $5 \%(v / v) \mathrm{CS}$ of the two strains and LA (1.32 mM) separately or without (NC) for $2 \mathrm{~h}$, followed by $1 \mathrm{mM} \mathrm{H}_{2} \mathrm{O}_{2}$ treatment for 0.5 and $2 \mathrm{~h}$ separately or not (blank). The mRNA expressions relative to the blank are shown as means $\pm \mathrm{SD}, n=3$. Asterisks indicate a significant difference with the blank, or between BF1-13 and the standard strain $\left({ }^{*} p<0.05\right)$ determined by the Mann-Whitney U test.

\subsection{Effect by LA Contained in the Metabolites Produced by Strain BF1-13 on the Intestinal Epithelial Barrier with $\mathrm{H}_{2} \mathrm{O}_{2}$ Treatment}

2.5.1. Protection on the Intestinal Epithelial Barrier by LA against the Dysfunction Caused by $\mathrm{H}_{2} \mathrm{O}_{2}$ Treatment

Equal concentration of authentic LA (1.32 mM), which was contained in the metabolites, included in the $5 \%(v / v)$ CS of strain BF1-13 indicated almost the same protective 
effect on decreasing TEER by $\mathrm{H}_{2} \mathrm{O}_{2}$ treatment on the model (Figure 7a). Supplementation of authentic LA $(1.32,1.97$, and $2.63 \mathrm{mM})$ suggested the significant maintenance effect of relative TEER values $\left(83 \%, 74 \%, 74 \%\right.$ ) on the model treated with $\mathrm{H}_{2} \mathrm{O}_{2}$ (Figure $7 \mathrm{~b}$ ). However, the protective effect of LA decreased by the higher concentration, which was more than $1.32 \mathrm{mM}$.

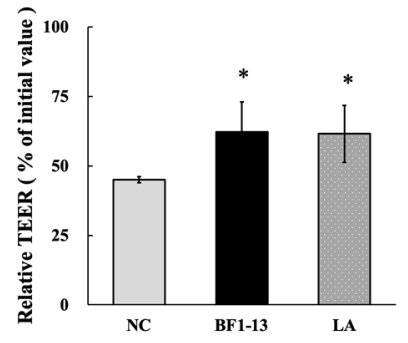

(a)

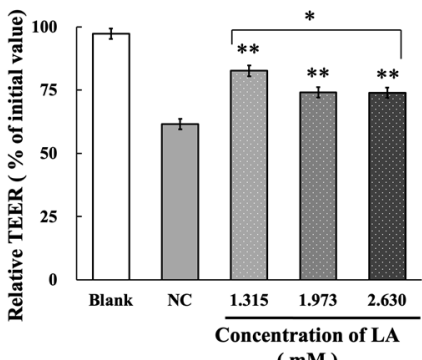

(b)

Figure 7. Protective effects of the metabolites of strain BF1-13 (black) and LA (spots) on TJs barrier function. (a) The comparison of the protective effect between $5 \%(v / v)$ CS and LA (1.32 mM) on TJs barrier function with $1 \mathrm{mM} \mathrm{H}_{2} \mathrm{O}_{2}$ (NC) or without (blank). (b) Dose-dependent protective effect of authentic LA on TJs barrier function. Monolayers were pre-incubated with 1.32, 1.97, and 2.63 mM authentic LA separately or without (NC) for $2 \mathrm{~h}$, followed by $1 \mathrm{mM} \mathrm{H}_{2} \mathrm{O}_{2}$ treatment for $6 \mathrm{~h}$ or not (blank). Relative TEER values are means $\pm \mathrm{SD}, n=3(\mathbf{a}), 6(\mathbf{b})$. Asterisks indicate a significant difference with NC $\left({ }^{*} p<0.05,{ }^{* *} p<0.005\right)$ determined by the Mann-Whitney $\mathrm{U}$ test, or among various concentrations of LA $(* p<0.01)$ determined by the Kruskal-Wallis test.

2.5.2. Enhancement on TJs-Related Proteins by LA Contained in the Metabolites Produced by Strain BF1-13

The CLDN-4 expression was maintained by the supplementation of the CS of strain BF1-13 and the equal concentration of authentic LA against $\mathrm{H}_{2} \mathrm{O}_{2}$ treatment (Figure 8). There was little difference in the effect between them. However, in the case of the equal concentration of authentic LA contained in the metabolites, the suppression of OCLN expression by the $\mathrm{H}_{2} \mathrm{O}_{2}$ treatment was relieved.

CLDN-4
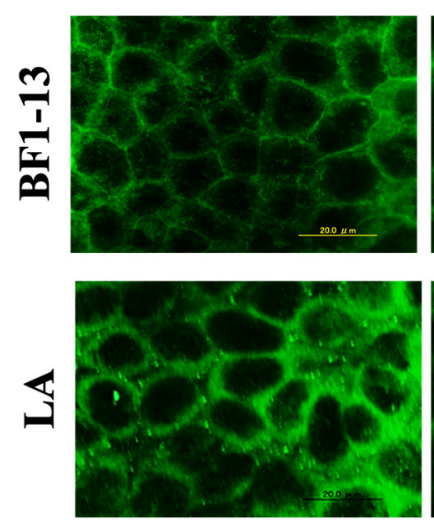

OCLN
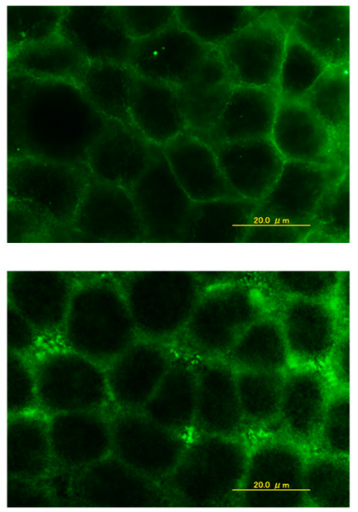

Figure 8. The comparison of the enhancements between the metabolites of strain BF1-13 and LA on the expression of CLDN-4 and OCLN. Monolayers were preincubated with $5 \%(v / v)$ CS of the strain and LA (1.32 mM) separately for $2 \mathrm{~h}$, followed by $1 \mathrm{mM} \mathrm{H}_{2} \mathrm{O}_{2}$ treatment for $2 \mathrm{~h}$. Images were observed by fluorescence microscopy. Each image is representative of 3 similar experiments. The scale bar is $20 \mu \mathrm{m}$.

The mRNA expression of CLDN-4 was induced by the supplementation with the CS of strain BF1-13. This effect was also shown in the equal concentration of authentic LA 
(fold-change of 1.55 \& 1.26) (Figure 9a). However, the mRNA expression of OCLN was only induced by the supplementation with LA at $0.5 \mathrm{~h}$ (fold-change of 1.25) (Figure 9b).

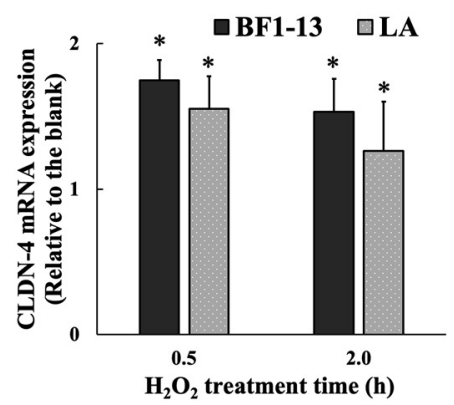

(a)

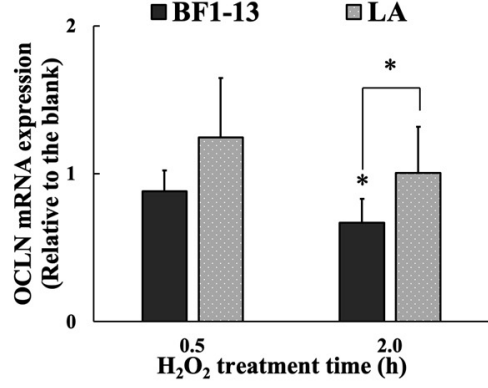

(b)

Figure 9. The comparison of the effect between the metabolites of strain BF1-13 (black) and LA (spots) on the expression of CLDN-4 (a) and OCLN (b) at the transcription level. Monolayers were preincubated with $5 \%(v / v)$ CS of strain BF1-13 and LA (1.32 mM) separately or without (NC) for $2 \mathrm{~h}$, followed by $1 \mathrm{mM} \mathrm{H}_{2} \mathrm{O}_{2}$ treatment for 0.5 and $2 \mathrm{~h}$ separately or not (blank). The mRNA expressions relative to the blank are shown as means $\pm \mathrm{SD}, n=3$. Asterisks indicate a significant difference with the blank, or between BF1-13 and LA $(* p<0.05)$ determined by the U-Mann-Whitney test.

\subsubsection{Effect on AQP3 by LA Contained in the Metabolites Produced by Strain BF1-13}

The LA (1.32 mM) contained in the metabolites of strain BF1-13 showed no suppressive effect on AQP3 expression (Figure 10) nor on its mRNA expression (Figure 11).

\section{AQP3}

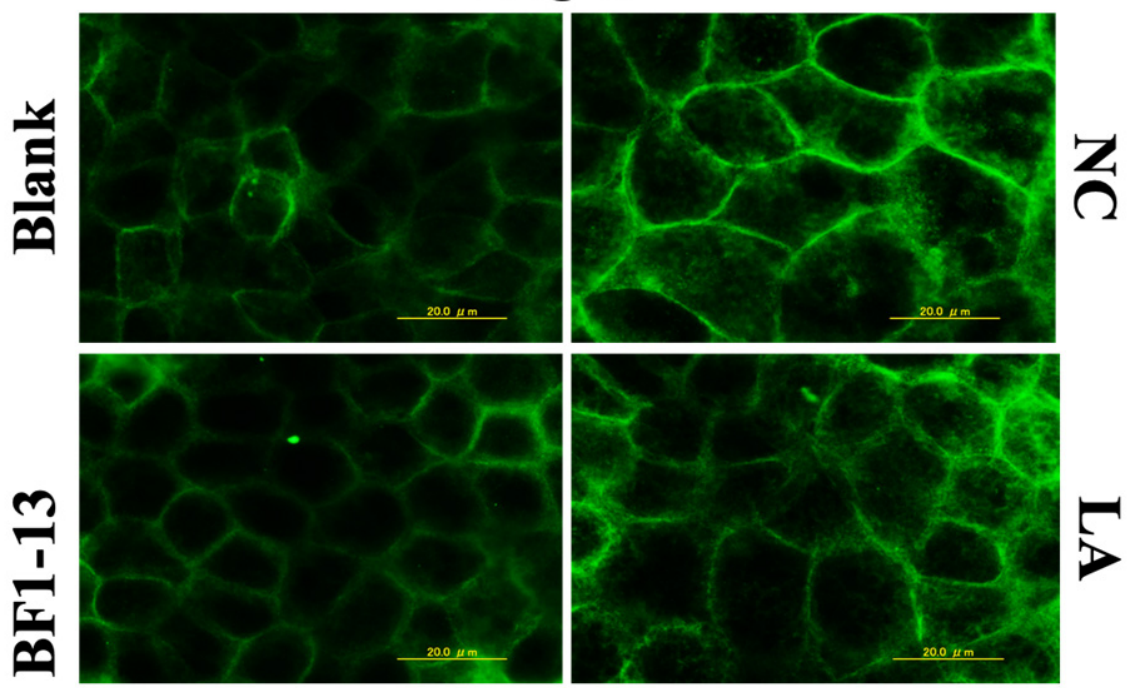

Figure 10. The effect of the metabolites of strain BF1-13 and equal concentration of authentic LA on the expression of APQ3 in human Caco-2 cells. Monolayers were preincubated with 5\% $(v / v)$ CS of the strain BF1-13 and LA (1.32 mM) separately or without (NC) for $2 \mathrm{~h}$, followed by $1 \mathrm{mM} \mathrm{H}_{2} \mathrm{O}_{2}$ treatment for $2 \mathrm{~h}$ or not (blank). Images were observed by fluorescence microscopy. Each image is representative of 3 similar experiments. The scale bar is $20 \mu \mathrm{m}$. 


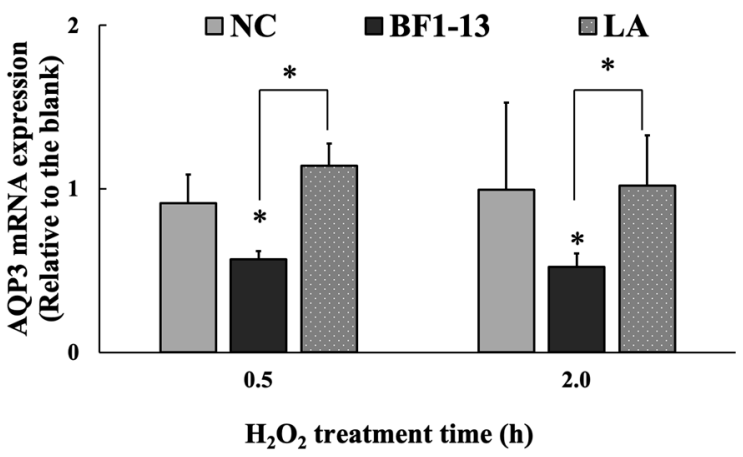

Figure 11. The effect of the metabolites of strain BF1-3 (black) and equal concentration of authentic LA (spots) on the expression of AQP3 at the transcription level. Monolayers were preincubated with $5 \%(v / v)$ CS of the strain BF1-13 and LA $(1.32 \mathrm{mM})$ separately or without (NC) for $2 \mathrm{~h}$, followed by $1 \mathrm{mM} \mathrm{H}_{2} \mathrm{O}_{2}$ treatment for 0.5 and $2 \mathrm{~h}$ separately or not (blank). The mRNA expressions relative to the blank are shown as means $\pm \mathrm{SD}, n=3$. Asterisks indicate a significant difference with the blank, or between BF1-13 and LA ( $p<0.05)$ determined by the U-Mann-Whitney test.

\section{Discussion}

The L. plantarum strain BF1-13 grew at a wide range of temperature $\left(27-40{ }^{\circ} \mathrm{C}\right)$ and $\mathrm{pH}(2-9)$, which also showed good tolerance to salt (up to $5 \% \mathrm{NaCl}$ ). The optimal culture conditions for L. plantarum strain BF1-13 were determined as the anaerobic incubation around $\mathrm{pH} 6.5$ at $37^{\circ} \mathrm{C}$. The LA contained in the CS after $12 \mathrm{~h}$ incubation of strain JCM11125 was less than that of strain BF1-13, which is consistent with the fact it can only convert $80 \%$ of the glucose into LA [22]. Good tolerance to low $\mathrm{pH}$ allows the strain BF1-13 to colonize in an acidic environment such as the human intestine. Its utilizing of the single carbohydrates source overcomes food intolerances during consumption, such as lactose intolerance. In summary, strain BF1-13 was suggested to have less limitation on both production and consumption when applied to different industries.

When the mechanism on the maintenance of human health via oral intake by the metabolites produced by marine-derived strain is studied, it is more practical to combine it with the transportation routes through the epithelial membrane during their absorptions in the small intestine. The small intestine is the main place for the nutrients to be taken up from the intestinal lumen to reach the lamina propria through the intestinal epithelium. In this study, all the tested samples were supplemented from the apical side, which stands for the lumen in vivo. As an endogenous reactive oxygen species, $\mathrm{H}_{2} \mathrm{O}_{2}$ is mostly produced in the lamina propria by antibacterial defense. Therefore, the monolayers in vitro model constructed by Caco-2 cells, which imitated the intestinal epithelial barrier, was treated with $\mathrm{H}_{2} \mathrm{O}_{2}$ from the basolateral side in this study. As a result, it was suggested by the relative TEER value that the metabolites produced by Lactiplantibacillus plantarum strain BF1-13 protected the intestinal epithelial barrier from the dysfunction caused by $\mathrm{H}_{2} \mathrm{O}_{2}$ treatment. The equal amount of LA included in the metabolites of strain BF1-13 also showed the same protective effect on the barrier. According to the results shown by immunofluorescence staining and quantitative RT-PCR, LA $(1.32 \mathrm{mM})$ contained in the CS of strain BF1-13 showed the similar enhancement on CLDN-4 expression at the transcription level with the metabolites themselves. In summary, it was suggested that LA, which was the only organic acid included in the metabolites produced by homofermentative LAB, was one of the bioactive substances to enhance the expression of TJs-related protein especially CLDN-4.

However, this enhancement on OCLN was much weaker than CLDN-4 especially by the supplementation of the CSs of two strains. This difference between CLDN-4 and OCLN was shown on both the protein expressions and the mRNA expression. To investigate why the protective effect on the barrier function of the intestinal epithelial model was achieved by the different enhancement on TJs expressions, further experiments related to the expression of AQP3, which was recently proven to facilitate $\mathrm{H}_{2} \mathrm{O}_{2}$ intracellular invasion, was prepared in this study [23]. It was known that AQP3 was expressed only on the 
basolateral side of the cell membrane [24]. Combining the positions of CLDN-4 and OCLN in TJs structure, it was indicated that $\mathrm{H}_{2} \mathrm{O}_{2}$ added to the basolateral side of the monolayer in the model had two different invasion routes, including intercellular invasion by simple passive diffusion and intracellular route by AQP3-facilitating diffusion. It was suggested that $\mathrm{H}_{2} \mathrm{O}_{2}$ intracellular invasion via APQ3 caused the suppression of the expression of TJs-related proteins, especially CLDN-4. It was also suggested that the suppression by the metabolites produced by the strain on AQP3 expression at the transcription level made the $\mathrm{H}_{2} \mathrm{O}_{2}$ preferentially target on OCLN via intercellular route than CLDN-4 via AQP3-facilitating intracellular invasion. The suppression was not shown by LA, mostly because, as a small molecule, it prefers the paracellular route by TJs rather than the transcellular route.

Lactiplantibacillus plantarum strain BF1-13 isolated from DSW in Izu-Akazawa was suggested to be a fast-growing strain with a higher LA accumulation compared to the same species strains isolated from surface seawater and terrestrial. According to this, strain BF1-13 was suggested to have the possibility of wide application in the LAB market. In addition, the protective effect of the metabolites produced by strain BF1-13 discovered by this study will provide the possibility of the application in the maintenance of human health against intestinal related diseases. Moreover, the relationship between the dysfunction of intestinal epithelium and $\mathrm{H}_{2} \mathrm{O}_{2}$ intracellular invasion has been revealed for the first time. This is the first time that LA has been reported to be an essential substance for the enhancement on the intestinal epithelial barrier from the dysfunction caused by $\mathrm{H}_{2} \mathrm{O}_{2}$, although many other effects of LA have been well-known. Still, the suppression of the AQP3 expression by the metabolites remains to be further researched.

\section{Materials and Methods}

\subsection{Chemicals}

High-glucose DMEM (HG-DMEM) was prepared with Dulbecco's modified Eagle's medium (DMEM; Nissui, Tokyo, Japan). De-Man Rogosa Sharpe medium (MRS broth, BD Difco $^{\mathrm{TM}}$, Sparks, MD, USA) was purchased for the incubation of LAB. Rabbit anti-CLDN-4, OCLN, AQP3 antibodies and horseradish peroxidase conjugated Goat anti-Rabbit IgG $\mathrm{H}+\mathrm{L}$ antibody were purchased from Abcam (Tokyo, Japan). Lactic acid and $\mathrm{H}_{2} \mathrm{O}_{2}$ was purchased from Wako (Osaka, Japan).

\subsection{Bacterial Strains and $16 S$ rRNA Sequencing}

Two isolated strains were prepared in the following methods in this study. L. plantarum strain BF1-13 was isolated by the DSW laboratory of DHC Co. from the bag filter (pore size, $0.5 \mu \mathrm{m}$ ) at $800 \mathrm{~m}$ depth DSW in the pumping station in Izu-Akazawa, Shizuoka Prefecture and strain H-6 was isolated from a seaweed 'Polyopes sp.' collected in Okinawa Prefecture. The genomic DNA used in the analysis of 16S rRNA gene sequences was extracted by Achromopeptidase (Wako, Osaka, Japan). Extracted DNA was PCR amplified by TKs Gflex DNA Polymerase (Takara Bio, Shiga, Japan) and was sequenced on ABI PRISM $3130 \times 1$ Genetic Analyzer System by using BigDye Terminator v3.1 Cycle Sequencing Kit (Applied Biosystems, Waltham, MA, USA). The 16S rDNA sequences were assembled using ChromasPro 2.1 (Technelysium, South Brisbane, AUS). Phylogenetic analysis was performed by using ENKI software (TechnoSuruga Laboratory, Shizuoka, Japan). Strain JCM11125 as the standard strain was obtained from RIKEN BRC (Ibaraki, Japan).

\subsection{Cell Culture}

Caco-2 cells (No. RCB0988, RIKEN BRC, Japan) were cultured by HG-DMEM at $37{ }^{\circ} \mathrm{C}$ in $5 \% \mathrm{CO}_{2}$. The cells at the density of $0.24 \times 10^{6}$ cells $/ \mathrm{cm}^{2}$ were seeded on each hanging cell culture insert (Millicell, $\Phi 6.5 \mathrm{~mm}, 1.0 \mu \mathrm{m}$ pore size, PET; $0.3 \mathrm{~cm}^{2}$ area; Merck KGaA, Darmstadt, Germany) to construct the intestinal epithelial model. The medium was changed every two days until the monolayer was completed. The cells used were between passage 11 and 25. 


\subsection{Bacteria Incubation and the Preparation of Metabolites Containing CSs from the Isolated Strains}

Both of the two strains and the standard strain were incubated in liquid MRS medium ( $\mathrm{pH}$ 6.5) at $37{ }^{\circ} \mathrm{C}$ for $12 \mathrm{~h}$ and the CSs were separately obtained from the bacterial suspension (with final bacterial concentrations of strains BF1-13 and JCM11125 as $1.67 \times 10^{9}$, $7.44 \times 10^{8} \mathrm{CFU} / \mathrm{mL}$, respectively) by centrifugation $\left(13,200 \times g, 4{ }^{\circ} \mathrm{C}, 5 \mathrm{~min}\right)$ followed by the sterilization through $0.2 \mu \mathrm{m}$ filter (ADVANTEC, Tokyo, Japan). For each CS, the ability of LA production by the strain was measured at $450 \mathrm{~nm}$ by a microplate reader (Model 550, Bio-Rad, Hercules, CA, USA) using Lactate Assay Kit-WST (DOJINDO, Kumamoto, Japan) after $\mathrm{pH}$ value was measured. The comparison of the growth temperature among three strains was investigated following the incubation at $5,10,20,27,37,40,45^{\circ} \mathrm{C}$, by using the MRS agar medium ( $\mathrm{pH}$ 6.5) for 2 weeks. Salt tolerance was investigated by $0 \sim 10 \%(\mathrm{~m} / \mathrm{v})$ $\mathrm{NaCl}$ supplementation to the MRS agar medium ( $\mathrm{pH}$ 6.5). Carbohydrate fermentation ability was conducted by using the nutrient-limited medium ( $\mathrm{pH}$ 6.5) containing different substrates $(0.4 \%, m / v)$ separately, including glucose, sorbitol, trehalose, xylose, arabinose, mannitol, and lactose. Salt tolerance, $\mathrm{pH}$ tolerance and carbohydrate fermentation ability of the strains were determined following the 2 weeks incubation at $37^{\circ} \mathrm{C}$.

\subsection{Measurement of the Intestinal TJs Barrier Function}

Intestinal epithelial barrier function was evaluated as the TEER value on the intestinal epithelial model using Caco-2 cells by Millicell-ERS-2 system (Millipore, Billerica, MA, USA). Caco-2 cells achieved to form the monolayer from 7 to 14 days after seeding when temperature corrected TEER (tcTEER) values of the model became stable around 200-300 $\Omega \mathrm{cm}^{2}$ (310.15 K) [25]. In this study, the CSs of the two strains were prepared with HG-DMEM separately as the evaluation medium. Each evaluation medium was added to the apical side of the membrane and the model was cultured for $2 \mathrm{~h}\left(37^{\circ} \mathrm{C}, 5 \%\right.$ $\left.\mathrm{CO}_{2}\right)$ to be habituated. After culturing, all the media in both apical and basolateral sides were replaced by HG-DMEM without FBS due to its eliminative effect of $\mathrm{H}_{2} \mathrm{O}_{2}$. Then, HG-DMEM (without FBS) containing $1 \mathrm{mM} \mathrm{H}_{2} \mathrm{O}_{2}$ (negative control, NC) or without $\mathrm{H}_{2} \mathrm{O}_{2}$ (blank) was added to the basolateral side. The model was incubated for $6 \mathrm{~h}\left(37^{\circ} \mathrm{C}, 5 \% \mathrm{CO}_{2}\right)$. TEER values were measured before and until $8 \mathrm{~h}$ of the CSs supplementation. Authentic LA $(1.32,1.97$, and $2.63 \mathrm{mM})$ prepared by HG-DMEM was also administered to the apical side following the same procedure to investigate its effect on TJs barrier function.

\subsection{Immunofluorescence Staining}

Cell monolayer was cultured separately with various evaluation media, including $5 \%(v / v)$ CSs of the two strains or authentic LA $(1.32 \mathrm{mM})$ for $2 \mathrm{~h}\left(37^{\circ} \mathrm{C}, 5 \% \mathrm{CO}_{2}\right)$ to be habituated. After culturing, all the media were replaced by HG-DMEM without FBS. Then, the model was treated without (blank) or with $1 \mathrm{mM} \mathrm{H}_{2} \mathrm{O}_{2}(\mathrm{NC})$ for $2 \mathrm{~h}\left(37^{\circ} \mathrm{C}, 5 \% \mathrm{CO}_{2}\right)$. After $\mathrm{H}_{2} \mathrm{O}_{2}$ treatment, the monolayers were rinsed with cold PBS, fixed in methanol at $4{ }^{\circ} \mathrm{C}$ for $30 \mathrm{~min}$. Next, they were exposed to PBS containing $0.3 \%$ Triton-X100 for $5 \mathrm{~min}$. Monolayers were blocked in PBS containing 5\% (v/v) normal fetal serum for $30 \mathrm{~min}$ at room temperature. The monolayers were separately incubated with rabbit anti-CLDN-4, OCLN, AQP3 antibody overnight at $4{ }^{\circ} \mathrm{C}$, followed by the 2 nd antibody (horseradish peroxidase conjugated goat anti-rabbit IgG $\mathrm{H}+\mathrm{L}$ antibody) for $1 \mathrm{~h}$ in the dark at room temperature. Each protein expression was observed by the fluorescence microscope with a magnification of 1000 (BX51N-33P, Olympus, Tokyo, Japan).

\subsection{RNA Extraction and Quantitative RT-PCR}

Confluent Caco- 2 cells were preincubated without (blank and NC) or with 5\% (v/v) $\mathrm{CS}$ of each strain or authentic LA $(1.32 \mathrm{mM})$ for $2 \mathrm{~h}\left(37^{\circ} \mathrm{C}, 5 \% \mathrm{CO}_{2}\right)$. After preincubation, all the media were replaced by HG-DMEM without FBS. Then, cells were treated with or without it (blank) $1 \mathrm{mM} \mathrm{H}_{2} \mathrm{O}_{2}$ for $0.5,1$, and $2 \mathrm{~h}$, separately $\left(37^{\circ} \mathrm{C}, 5 \% \mathrm{CO}_{2}\right)$. After $\mathrm{H}_{2} \mathrm{O}_{2}$ treatment, total RNA was extracted using ISOGENII (NIPPON GENE, Tokyo, Japan) according to the supplier's protocol by using sterile and RNase-free tubes. Total RNA 
was quantified by measuring optical density at $260 \mathrm{~nm}$. cDNAs were synthesized using $1 \mu \mathrm{g}$ total RNA by PrimeScriptTM Reverse Transcriptase (TaKaRa, Shiga, Japan) following the instruction. Quantitative RT-PCR was conducted with $2 \mu \mathrm{L}$ cDNA template in a total volume of $20 \mu \mathrm{L}$ by TB Green ${ }^{\circledR}$ Fast qPCR Mix (TaKaRa, Shiga, Japan) using Applied Biosystems ${ }^{\circledR}$ StepOnePlusTM Real-Time PCR Systems (Thermo Fisher, Waltham, MA, USA) with specific primers of each gene (Table S1). PCR reaction for each sample was done in triplicate in 96-well plates. Gene expression was normalized to glyceraldehyde-3-phosphate dehydrogenase (GAPDH) and calculated by the comparative CT method to be expressed as fold-change compared to the blank.

\subsection{Statistical Analysis}

All the tcTEER values were indicated as relative TEER values by which the initial values were $100 \%$. All values were indicated as mean \pm SD. Statistical significance was determined by the U-Mann-Whitney test for the comparison between two groups and the Kruskal-Wallis test for that among groups.

\section{Conclusions}

In summary, metabolites produced by DSW-derived Lactiplantibacillus plantarum strain BF1-13 protect the intestinal epithelial barrier from the dysfunction caused by $\mathrm{H}_{2} \mathrm{O}_{2}$ treatment. It was also elucidated that the mechanism of this protective effect was achieved by both the enhancement of CLDN-4 expression and the suppression on AQP3-facililating $\mathrm{H}_{2} \mathrm{O}_{2}$ invasion. The oxidative stress induced by $\mathrm{H}_{2} \mathrm{O}_{2}$ impairs the intestinal epithelial barrier function which is mainly regulated by TJs, especially CLDN-4 [26]. The dysfunction of the intestinal epithelial barrier is correlated to the IBD, including ulcerative colitis (limited to the large intestine) and Crohn's disease (mainly affects the small intestine), which correlates with a higher risk for colorectal cancer [27]. For the people who are at risk of IBD that could be triggered by both genetic susceptibility and environmental exposure [28], the daily intake of the food fermented by the strain BF1-13 could help them with maintaining the intestinal epithelial barrier function to lower the risk. For the patients who are suffering the prolonged inflammation, metabolites produced by the strain could be the supplements to support them in the daily diet or help them recover from the surgical treatment.

Supplementary Materials: The following supporting information can be downloaded at: https: / / www.mdpi.com/article/10.3390/md20020087/s1, Table S1: Sequences of primers (human) used for quantitative RT-PCR.

Author Contributions: Conceptualization, X.D. and K.Y.; methodology, X.D. and K.Y.; software, X.D. and K.Y.; validation, X.D.; formal analysis, X.D., K.Y., Y.S. and C.I.; investigation, X.D. and K.Y.; resources, K.Y., Y.S. and C.I.; data curation, X.D. and K.Y.; writing-original draft preparation, X.D.; writing-review and editing, K.Y., C.I.; visualization, X.D. and K.Y.; supervision, X.D. and K.Y.; project administration, K.Y. and C.I.; funding acquisition, X.D. All authors have read and agreed to the published version of the manuscript.

Funding: This research received no external funding.

Institutional Review Board Statement: Not applicable.

Informed Consent Statement: Not applicable.

Data Availability Statement: The data that support the administration concentration of hydrogen peroxide used in this study are openly available at http:/ / doi.org/10.2741/3223 (accessed on 1 May 2008).

Acknowledgments: Thanks to Nomura, M. and Yamamoto, T. for giving advice on the research. Also, thanks to Terahara, T. for the instruction on the quantitative RT-PCR.

Conflicts of Interest: The authors declare no conflict of interest. 


\section{References}

1. König, J.; Wells, J.; Cani, P.; García-Ródenas, C.; MacDonald, T.; Mercenier, A.; Whyte, J.; Troost, F.; Brummer, R. Human Intestinal Barrier Function in Health and Disease. Clin. Transl. Gastroenterol. 2016, 7, e196. [CrossRef] [PubMed]

2. Camilleri, M.; Madsen, K.; Spiller, R.; Van Meerveld, B.; Verne, G. Intestinal Barrier Function in Health and Gastrointestinal Disease. Neurogastroenterol. Motil. 2012, 24, 503-512. [CrossRef] [PubMed]

3. Natsuga, K. Epidermal Barriers. Cold Spring Harb. Perspect. Med. 2014, 4, a018218. [CrossRef] [PubMed]

4. Liévin-Le Moal, V.; Servin, A. Pathogenesis of Human Enterovirulent Bacteria: Lessons from Cultured, Fully Differentiated Human Colon Cancer Cell Lines. Microbiol. Mol. Biol. Rev. 2013, 77, 380-439. [CrossRef]

5. Srinivasan, B.; Kolli, A.; Esch, M.; Abaci, H.; Shuler, M.; Hickman, J. TEER Measurement Techniques For In Vitro Barrier Model Systems. J. Lab. Autom. 2015, 20, 107-126. [CrossRef]

6. Birben, E.; Sahiner, U.; Sackesen, C.; Erzurum, S.; Kalayci, O. Oxidative Stress and Antioxidant Defense. WAO J. 2012, 5, 9-19. [CrossRef]

7. Saeidnia, S.; Abdollahi, M. Toxicological and Pharmacological Concerns on Oxidative Stress and Related Diseases. Toxicol. Appl. Pharm. 2013, 273, 442-455. [CrossRef]

8. Sies, H. Role of metabolic $\mathrm{H}_{2} \mathrm{O}_{2}$ generation: Redox signaling and oxidative stress. J. Biol. Chem. 2014, 289, 8735-8741. [CrossRef]

9. Rao, R. Oxidative Stress-Induced Disruption of Epithelial and Endothelial Tight Junctions. Front. Biosci. 2008, 13, 7210-7226. [CrossRef]

10. Bienert, G.; Chaumont, F. Aquaporin-Facilitated Transmembrane Diffusion of Hydrogen Peroxide. Biochim. Biophys. Acta 2014, 1840, 1596-1604. [CrossRef]

11. Jandhyala, S.M.; Talukdar, R.; Subramanyamet, C.; Vuyyuru, H.; Sasikala, M.; Reddy, D.N. Role of the normal gut microbiota. World J. Gastroenterol. 2015, 21, 87887-88803. [CrossRef] [PubMed]

12. Ghaffar, T.; Irshad, M.; Anwar, Z.; Aqil, T.; Zulifqar, Z.; Tariq, A.; Kamran, M.; Ehsan, N.; Mehmood, S. Recent Trends in Lactic Acid Biotechnology: A Brief Review on Production to Purification. J. Radiat. Res. Appl. Sci. 2014, 7, 222-229. [CrossRef]

13. Alves de Oliveira, R.; Komesu, A.; Vaz Rossell, C.; Maciel Filho, R. Challenges and Opportunities in Lactic Acid Bioprocess Design-From Economic to Production Aspects. Biochem. Eng. J. 2018, 133, 219-239. [CrossRef]

14. Grishina, A.; Kulikova, I.; Alieva, L.; Dodson, A.; Rowland, I.; Jin, J. Antigenotoxic Effect of Kefir and Ayran Supernatants on Fecal Water-Induced DNA Damage in Human Colon Cells. Nutr. Cancer. 2011, 63, 73-79. [CrossRef]

15. Bengoa, A.A.; Iraporda, C.; Garrote, G.L.; Abraham, A.G. Kefir micro-organisms: Their role in grain assembly and health properties of fermented milk. J. Appl. Microbiol. 2018, 126, 686-700. [CrossRef]

16. Forsyth, G.; Kapitany, R.; Hamilton, D. Organic Acid Proton Donors Decrease Intestinal Secretion Caused by Enterotoxins. Am. J. Physiol. Gastrointest. Liver Physiol. 1981, 241, G227-G234. [CrossRef]

17. Seth, A.; Yan, F.; Polk, D.; Rao, R. Probiotics Ameliorate the Hydrogen Peroxide-Induced Epithelial Barrier Disruption by A PKCAnd MAP Kinase-Dependent Mechanism. Am. J. Physiol. Gastrointest. Liver Physiol. 2008, 294, G1060-G1069. [CrossRef]

18. Miyauchi, E.; O'Callaghan, J.; Buttó, L.; Hurley, G.; Melgar, S.; Tanabe, S.; Shanahan, F.; Nally, K.; O’Toole, P. Mechanism of Protection of Transepithelial Barrier Function By Lactobacillus salivarius: Strain Dependence and Attenuation by Bacteriocin Production. Am. J. Physiol. Gastrointest. Liver Physiol. 2012, 303, G1029-G1041. [CrossRef]

19. Yoda, K.; Miyazawa, K.; Hosoda, M.; Hiramatsu, M.; Yan, F.; He, F. Lactobacillus GG-Fermented Milk Prevents DSS-Induced Colitis and Regulates Intestinal Epithelial Homeostasis through Activation of Epidermal Growth Factor Receptor. Eur. J. Nutr. 2013, 53, 105-115. [CrossRef] [PubMed]

20. Pohanka, M. D-Lactic Acid as A Metabolite: Toxicology, Diagnosis, And Detection. BioMed. Res. Int. 2020, $2020,3419034$. [CrossRef] [PubMed]

21. Kostinek, M.; Pukall, R.; Rooney, A.; Schillinger, U.; Hertel, C.; Holzapfel, W.; Franz, C. Lactobacillus arizonensis Is a Later Heterotypic Synonym of Lactobacillus plantarum. Int. J. Syst. Evol. Microbiol. 2005, 55, 2485-2489. [CrossRef]

22. Swezey, J.; Nakamura, L.; Abbott, T.; Peterson, R. Lactobacillus arizonensis Sp. Nov., Isolated from Jojoba Meal. Int. J. Syst. Evol. Microbiol. 2000, 50, 1803-1809. [CrossRef]

23. Bollag, W.; Aitkens, L.; White, J.; Hyndman, K. Aquaporin-3 in the Epidermis: More Than Skin Deep. Am. J. Physiol. Cell Physiol. 2020, 318, C1144-C1153. [CrossRef] [PubMed]

24. Rai, T.; Sasaki, S.; Uchida, S. Polarized Trafficking of the Aquaporin-3 Water Channel Is Mediated by An $\mathrm{NH}_{2}-\mathrm{Terminal} \mathrm{Sorting}$ Signal. Am. J. Physiol. Cell Physiol. 2006, 290, C298-C304. [CrossRef] [PubMed]

25. Blume, L.F.; Denker, M.; Gieseler, F.; Kunze, T. Temperature Corrected Transepithelial Electrical Resistance (TEER) Measurement to Quantify Rapid Changes in Paracellular Permeability. Pharmazie 2010, 65, 19-24. [PubMed]

26. Landy, J.; Ronde, E.; English, N.; Clark, S.; Hart, A.; Knight, S.; Ciclitira, P.; Al-Hassi, H. Tight Junctions In Inflammatory Bowel Diseases And Inflammatory Bowel Disease Associated Colorectal Cancer. World J. Gastroenterol. 2016, 22, 3117-3126. [CrossRef] [PubMed]

27. Nadeem, M.S.; Kumar, V.; Al-Abbasi, F.A.; Kamal, M.A.; Anwar, F. Risk of Colorectal Cancer in Inflammatory Bowel Diseases. Semin. Cancer Biol. 2020, 64, 51-60. [CrossRef] [PubMed]

28. Gu, P.; Feagins, L. Dining With Inflammatory Bowel Disease: A Review of the Literature on Diet in the Pathogenesis and Management of IBD. Inflamm. Bowel Diseases. 2019, 26, 181-191. [CrossRef] 